\title{
Mediação docente na educação de jovens, Adultos e idosos
} Teaching mediation in the education of young, aged and adults

\author{
Mediación de maestros en la educación de jovenes, adultos y \\ mayores
}

\author{
Paula Roberta Miranda ${ }^{1}$
}

\begin{abstract}
RESUMO
Este trabalho tem como objetivo investigar como o ensino organizado e desenvolvido no âmbito escolar pode se constituir em situações que promovam a aprendizagem de conteúdos que se transformem em elementos mediadores do pensamento dos estudantes, ou seja, como o ensino pode ser promotor do desenvolvimento. Para a sua execução, foram realizados estudos bibliográficos e observações de vinte horas/aula, cujo conteúdo trabalhado foi reprodução humana, em uma sala multisseriada de Educação de Jovens e Adultos da $1^{\mathrm{a}}$ à $4^{\mathrm{a}}$ série do ensino fundamental de uma escola pública do Estado do Paraná. Os dados foram analisados tomando-se como referência a Teoria Histórico-Cultural, abordagem segundo a qual a aprendizagem adequadamente organizada leva ao desenvolvimento das capacidades complexas do pensamento, e a mediação se refere tanto aos instrumentos, como aos signos e às relações que o sujeito estabelece com os outros. Portanto, mediação é um fator preponderante nos processos de ensino $e$ aprendizagem. As análises apontam que o ensino sistematizado de conceitos científicos concorre para a formação que ultrapassa o caráter meramente adaptativo, quando os estudantes, ao tomarem consciência dos conceitos, tornam-se capazes de pensar e agir com eles.

Palavras-chave: mediação; ensino; educação de jovens e adultos.
\end{abstract}

\begin{abstract}
Current research involves school-organized teaching and investigates whether it promotes content learning that transforms itself in mediating factors of thought in the students. Research discusses the manner teaching as a promoter of development. Bibliographical studies and 20-hour class observations were undertaken on human reproduction in a multi-series class with young people and adults of the first grades of the primary school in a government school in the state of Paraná, Brazil. Data were analyzed according to the Historical and Cultural Theory. This approach provides that properly organized learning leads towards development of the complex abilities of thought, while mediation comprises tools, signs and relationships that the subject maintains with the others. Mediation is therefore an important factor in teaching and learning processes. Analysis shows that the systemized teaching of scientific concepts leads towards a training that goes beyond the merely adaptive stage when students, aware of the concepts, are able to think and act accordingly. Key words: mediation; teaching; education for young people and adults.
\end{abstract} \begin{tabular}{l}
\hline Mestre em Educação pela Universidade Estadual de Maringá (UEM). Av. José Alves Nendo, 1256, Bl. 08, apt ${ }^{\circ}$ 02, Jd. São Silvestre, \\
Maringá-PR - (44) 30347326, (44) 99578183. E-mail: paula_rmiranda@ hotmail.com
\end{tabular} 


\section{Introdução}

Nas discussões sobre as práticas docentes, a mediação é um dos aspectos que, geralmente, são destacados. Ao analisarmos as tendências pedagógicas que subsidiam tais práticas, notamos que a educação escolar está perpassada por uma concepção de ensino, aprendizagem, relação professor/aluno, conteúdos ligados aos objetivos que se almejam em termos de formação.

Nas últimas décadas, percebemos que a Teoria Histórico-Cultural, tem orientado um número cada vez maior de pesquisas, estudos, sobretudo, os mais direcionados aos processos de ensino e aprendizagem. Nesse âmbito, a mediação, passou a ser considerada como uma possibilidade de inovação pedagógica.

Os fundamentos dessa Teoria trazem contribuições importantes à medida que rompem com ideias construídas ao longo do tempo, e legitimada por teorias, por exemplo, a de que o sujeito constrói o seu próprio conhecimento $e$ que o mais importante é fazer com que o aluno aprenda a aprender. Destacamos ainda que, segundo a abordagem Histórico-Cultural, a cultura se constitui elemento especial no processo de formação e desenvolvimento dos sujeitos, contrariando teorias que defendem o desenvolvimento psíquico sem considerar as experiências adquiridas no contexto sociocultural.

Apesar de se ter consolidado a ideia da importância da mediação docente, perece-nos que este conceito não tem sido compreendido tal como é concebido pela Teoria Histórico-Cultural. A ênfase tem recaído mais sobre a relação com o outro - um dos aspectos. O conteúdo, ou seja, os conceitos que são objetos do ensino não têm recebido a mesma atenção.

Na perspectiva Histórico-Cultural, a mediação se refere sim à relação com o outro, mas diz respeito também aos instrumentos $e$ signos mediadores, ou seja, aos elementos que se interpõem entre o sujeito e o meio, orientando, tanto suas ações externas, como as ações internas, as psicológicas.

Não podemos negar o fato de que em qualquer processo de ensino ocorre mediação, entendida no seu sentido amplo, pois sempre há ensino. Todavia, os objetivos da educação e do ensino se diferem, tendo em vista a formação que se está almejando.

Essas questões, aliadas às observações diárias no trabalho com educação de jovens e adultos, levaram-nos a buscar respostas para as seguintes questões: que objetivos em termos de formação têm perpassado o ensino para jovens e adultos? Como o ensino pode ser organizado de modo a favorecer uma aprendizagem promotora do desenvolvimento? Assim, este trabalho tem como objetivo analisar o ensino no processo de aprendizagem, ou seja, investigar como as atividades de ensino, organizadas e desenvolvidas no espaço escolar, podem se constituir em situações que promovam a aprendizagem de conteúdos que se transformem em elementos mediadores do pensamento.

O que substancia esse trabalho é a dissertação da autora que trata da mediação e processo de aquisição do conhecimento na educação de jovens e adultos e sua vinculação, entre 2004 e 2008, na EJA Fase I ( $1^{\mathrm{a}}$ à $4^{\mathrm{a}}$ séries) como coordenadora pedagógica. Desse modo, esse artigo não pretende definir tendências pedagógicas ou teorias, mas utilizar esse espaço como uma possibilidade de reflexão da prática pedagógica de professores, pedagogos e demais profissionais que atuam na EJA.

A Constituição Federal e a LDB/96 asseguram como direito de todos o acesso ao ensino fundamental, obrigatório e gratuito, inclusive para aqueles que não o tiveram na idade adequada. Nos últimos anos, observa-se um avanço significativo nos indicadores educacionais. As estatísticas têm mostrado que há um contingente maior de pessoas frequentando a 
escola, muitos, inclusive, retornando depois de adultos.

Uma verificação mais detalhada sobre a escolaridade dos brasileiros mostra que, se por um lado, houve o atendimento a uma quase totalidade da população, garantindo o acesso previsto pela constituição, por outro lado, ainda é grande o número de pessoas que não concluíram o ensino fundamental obrigatório.

Em nosso país há milhares de pessoas com idade superior a catorze anos que não completaram quatro anos de escolaridade. Esse contingente constitui o público potencial dos programas da educação de jovens e adultos correspondentes ao primeiro segmento do ensino fundamental.

Em se tratando da educação de jovens, adultos e idosos, sabemos que esses alunos desenvolveram, ao longo da vida, saberes, estratégias, modos de convivência e sobrevivência sem, necessariamente, passarem pela escolarização, pelo ensino sistematizado. Embora o aluno esteja inserido na sociedade, esses saberes, apesar de válidos e úteis à vida prática, não são suficientes para que os sujeitos possam agir conscientemente no mundo em que vivem. A ausência ou o pouco contato com o ensino escolar faz com que esses sujeitos apresentem dificuldades para analisarem cientificamente fatos e fenômenos para além dos dados empíricos.

Pensando nessas questões, buscamos respaldo no conceito de mediação defendido pela teoria Histórico-Cultural que, pela sua configuração, pode ajudar na compreensão de questões que envolvem a aprendizagem de estudantes dessa modalidade de ensino, à medida que os conceitos espontâneos, ao serem superados pelos científicos, se tornem instrumentos do pensamento, ou seja, em elementos mediadores entre o sujeito e o mundo, possibilitando os estudantes pensarem e agirem conscientemente sobre os fatos da realidade.
Conceitos espontâneos e sistematizados: a relevância do ensino no processo de apropriação dos conceitos sistematizados

Os conceitos espontâneos, por se desenvolverem em situações cotidianas, imediatas, apoiadas na observação ou manipulação direta do objeto, envolvem o pensamento empírico, ligando-se a traços sensoriais do objeto. As pessoas lidam com esses conceitos de forma inconsciente de seu próprio ato de pensamento, não têm domínio sobre ela, pois estar consciente da atividade significa poder atuar sobre ela de forma deliberada. Por essa razão, os saberes empíricos, espontâneos, nem sempre possibilitam a compreensão dos fatos e dos fenômenos presentes na realidade.

Já a aquisição dos conceitos científicos acontece mediante o processo de apropriação de conhecimentos sistematizados por instituições especializadas. "Começam na esfera do caráter consciente e da intencionalidade e dirigem-se à esfera da experiência pessoal e do concreto" (SFORNI, 2004, p. 78). Dessa forma, a apropriação dos conceitos científicos promove o desenvolvimento psíquico do sujeito. Ao operar com os conceitos cotidianos a ação mental está voltada para o objeto, para o fenômeno e não para o próprio ato de pensamento em que está inserido. Isto quer dizer que esses conceitos ainda não estão conscientes na esfera cognitiva. "A aprendizagem dos conceitos científicos exige operações mentais complexas que dirigem a consciência ao próprio conceito, ao ato do pensamento" (PALANGANA; GALUCH; SFORNI, 2002, p. 117). O ensino de natureza escolar possibilita o acesso ao conceito científico, portanto, é um conhecimento que é adquirido diferentemente da forma como é adquirida a experiência imediata, ou seja, tem uma intencionalidade, uma organização com o fim específico de ensinar e aprender, pois a aquisição dos conceitos científicos é sempre mediada por outros conceitos elaborados anteriormente. 
De acordo com Vygotski (1993), no âmbito dos conceitos científicos, o nível de consciência é mais elevado que no nível dos conceitos espontâneos. O desenvolvimento dos conceitos científicos segue um caminho particular, ocorrendo em condições de ensino, com a participação e colaboração do outro.

Poder-se-ia dizer que o desenvolvimento dos conceitos espontâneos da criança é ascendente, enquanto o desenvolvimento dos seus conceitos científicos é descendente, para um nível mais elementar e concreto. Isso decorre das diferentes formas pelas quais os dois tipos de conceitos surgem (VYGOTSKY, 1989, p. 93).

Os conceitos cotidianos são formados nos enfrentamentos da criança com o mundo. Têm início na esfera do concreto, do empírico. Em princípio, mesmo a criança tendo consciência dos conceitos e desenvolvido capacidades intelectivas como a memória e a atenção, ainda não é capaz de tomar consciência dos processos de seu próprio pensamento, utilizando-se esses conceitos de forma inconsciente, porque sua atenção está centrada no objeto ao qual o conceito se refere e não no próprio ato do pensamento. "As crianças sabem operar espontaneamente com eles e não tomam consciência deles. [...] a atenção nele contida está sempre orientada para o objeto nele representado e não para o próprio ato de pensar que abrange" (VYGOTSKY, 2000, p. 290).

Inversamente do que ocorre com os conceitos cotidianos,

Os conceitos científicos - com sua relação inteiramente distinta com o objeto - mediados por outros conceitos - com seu sistema hierárquico interior de inter-relações -, são o campo em que a tomada de consciência dos conceitos, ou melhor, a sua generalização e a sua apreensão parecem surgir antes de qualquer coisa. Assim surgida em um campo do pensamento, a nova estrutura da generalização, como qualquer estrutura, é posteriormente transferida como um princípio de atividade sem nenhuma memorização para todos os outros campos do pensamento e dos conceitos. Desse modo, a tomada de consciência passa pelos portões dos conceitos científicos (VYGOTSKY, 2000, p. 290).

Estes são autênticos atos complexos de pensamento. Todavia, os conceitos não podem ser ensinados por meio de treinamento, porque envolvem atenção deliberada, abstração, memória lógica, capacidade de comparação $e$ diferenciação. Por esta razão, "[...] a formação dos conceitos é resultado de uma complexa atividade em que todas as funções intelectuais fundamentais participam" (VYGOTSKY, 1979, p. 82).

A articulação dos conceitos cotidianos com os científicos possibilita um tipo de percepção mais generalizante, que conscientiza o sujeito de seus processos mentais, impulsionando seu desenvolvimento. A transmissão de conceitos sistemáticos supõe um ensino que dirija a atenção do estudante para aspectos que não se revelam por si mesmos, aspectos que não são perceptíveis pelo simples fato de o aluno estar diante do objeto ou fenômeno, nem tampouco porque os vivenciou.

Nisto reside a essência do conceito
científico. Este seria desnecessário se
refletisse o objeto em sua manifestação
externa como conceito empírico. Por
isso o conceito científico pressupõe
necessariamente outra relação com
objetos, só possível no conceito, e esta
outra relação com o objeto, contida no
conceito científico, por sua vez pres-
supõe necessariamente a existência de
relações entre os conceitos, ou seja, um
sistema de conceitos [...] Assim, uma 
criança costuma aprender a palavra 'flor' antes da palavra 'rosa'. Mas neste caso o conceito 'flor' não é na criança mais genérico que a palavra 'rosa', é apenas mais amplo. É claro que quando a criança dispõe apenas de um conceito e sua relação com o objeto é diferente de quando ela dispõe de um segundo conceito. Mas também depois disso o conceito 'flor' continua durante muito tempo ao lado do conceito 'rosa', e não sobreposto a ele. Não incorpora o conceito mais particular nem o subordina a si mesmo, mas o substitui e o dispõe em uma série consigo mesmo. Quando surge a generalização do conceito 'flor', modifica-se também a relação entre 'flor' e 'rosa' assim como entre outros conceitos subordinados (VYGOTSKY, 2000, p. 294).

Os conceitos científicos possibilitam àquele que os adquire a consciência reflexiva, que se transfere aos conhecimentos comuns.

Nessa perspectiva, Moura escreve:

A cultura e a escola, particularmente, desenvolvem no homem métodos cada vez mais novos, criam provisões de experiências, implantam grandes números de métodos auxiliares complexos e sofisticados, possibilitando que todas as funções se transformem de naturais em 'culturais'. É na fase de escolarização básica, e principalmente, durante a escolarização do adolescente, que esse processo provoca uma marca fundamental no desenvolvimento $e$ consolidação das 'funções psicológicas superiores de inteligência' (MOURA, 1999, p. 179).

Nas atividades de aprendizagem adequadamente organizadas, o estudante, aos poucos, vai abstraindo e generalizando os traços essenciais dos objetos, compreendendo-os como categorias conceituais. Os conceitos cotidianos são, na escola, aos poucos, elevados à condição de conceitos científicos e estes, por já estarem sistematizados descem até o nível dos conceitos cotidianos.

Nesse sentido, cabe à escola promover a articulação dos conceitos cotidianos com os científicos, de modo que, de um lado, os conceitos cotidianos possam alcançar os científicos e, de outro lado, os conceitos científicos tornem-se mais concretos, porque compreendidos, criando, assim, condições para que os alunos os generalizem para situações não escolares. Quando o aluno se apropria do conceito, ele consegue pensar e agir com ele, não apenas repeti-lo em situações de avaliação escolar. Nisso consiste o papel do ensino quando se tem como objetivo uma aprendizagem promotora do desenvolvimento.

\section{Conforme Kostiuk:}

O domínio de conceitos cada vez mais complexos favorece o desenvolvimento da abstracção e da generalização, conduz à formação e ao aperfeiçoamento de operações lógicas, ao desenvolvimento da curiosidade, à iniciativa e à independência na assimilação de conhecimentos (KOSTIUK 1991, p. 55).

Conceitos científicos e espontâneos: como agem os adultos pouco escolarizados?

A reflexão sobre a aprendizagem de adultos pouco escolarizados, nos remete ao fato de que se trata de sujeitos que trazem consigo uma gama de conhecimentos e concepções sobre os fenômenos e os fatos que foram sendo acumulados nas experiências e vivências cotidianas.

Segundo Oliveira (2001), são adultos que utilizam, diariamente, várias estratégias para enfrentar os desafios da vida e lidar com processos mais complexos. Por outro lado, o processo de aquisição de novos conhecimentos torna-se complicado diante dos conhecimentos espontâneos estabilizados, e que de certa forma 
funcionam como "comandos" para proceder diante de situações da vida cotidiana.

Nesse sentido, adultos pouco escolarizados adquirem os conceitos cotidianos de forma verbal, nos saberes práticos, todavia, apesar de válidos e úteis à vida prática, esses mesmos conceitos não são suficientes para desencadear nos adultos um processo de reflexão cuja base seja o pensamento conceitual. Os conceitos espontâneos estão relacionados diretamente aos objetos, às situações imediatas, logo, os sujeitos lidam com eles de forma inconsciente. Opostamente a isso, os conceitos científicos, apesar de estarem intimamente relacionados aos conceitos cotidianos, uma vez que estão implícitos neles, percorrem caminhos diferentes para o seu desenvolvimento: são desenvolvidos em situações possibilitadas pelo ensino de natureza escolar; iniciam na esfera da consciência e da intencionalidade, possibilitando a abstração de seus traços essenciais e a generalização, elementos que conduzem ao verdadeiro conceito.

Investigações realizadas por Luria (1990) sobre a relação entre cultura e pensamento fornecem elementos com os quais podemos perceber a escolarização como fator fundamental na definição das diferenças culturais. Sua pesquisa, realizada com crianças e adultos com pouca ou nenhuma escolarização, consistiu em verificar quais as interferências que o meio físico e social (influências culturais e educacionais) trazem para o desenvolvimento das funções psicológicas superiores dos indivíduos. Luria concluiu que indivíduos analfabetos, cujas atividades eram mais "práticas", permaneciam "presos" a situações imediatas, ao pensamento situacional, não conseguindo estabelecer relações entre os objetos de modo a classificá-los em categorias conceituais, isto é, não alcançavam o pensamento teórico. Por outro lado, os indivíduos que tinham tido alguma experiência escolar, ainda que ínfima, ou desenvolviam algum trabalho coletivo, tinham mais facilidade em transitar entre as categorias conceituais e chegar ao pensamento teórico; eram capazes de estabelecer relações entre os objetos, de modo a generalizá-los.

Diante dessas questões, cabe-nos um questionamento: se é na aquisição dos conceitos científicos, possibilitada pelo ensino sistematizado, que o indivíduo desenvolve suas capacidades intelectuais e alcança níveis mais elevados de pensamento, como podemos organizar o ensino de modo que os conhecimentos se constituam em instrumento do pensamento de adolescentes, jovens e adultos com pouca escolarização, sem que o objetivo maior seja uma formação adaptativa?

\section{Mediação docente no ensino de conceitos sistematizados na educação de jovens e adultos}

Fundamentando-nos na ideia vygotskyana de que "[...] o aprendizado adequadamente organizado resulta em desenvolvimento mental e põe em movimento vários processos de desenvolvimento que, de outra forma, seriam impossiveis de acontecer" (VYGOTSKY 1989), analisamos os dados obtidos na $4^{a}$ série do ensino fundamental, por meio de observações de 20 horas/aulas de ciências, ministradas a um grupo de 20 alunos do primeiro segmento da educação de jovens e adultos $\left(1^{\mathrm{a}}\right.$ à $4^{\mathrm{a}}$ série do ensino fundamental), com faixa etária entre $15 \mathrm{e}$ 60 anos, numa escola pública do Estado do Paraná. Durante as aulas observadas, a professora trabalhou com o tema "Reprodução Humana".

Neste trabalho vamos nos limitar a apresentar a mediação docente realizada em uma das aulas, em que a professora trabalhou sobre como são produzidos os ovários, utilizando um texto com esse mesmo título.

Professora: Vamos entender o porquê ocorre a menstruação ou não. 
Professora: Em que situações ela ocorre? Por que ficamos menstruadas?

Aluno 18: Quando não há ovulação. Professora: Vocês já sabem o caminho que o espermatozóide percorre até ser eliminado do corpo do homem, mas no corpo da mulher, que caminho o espermatozóide faz?

Aluno 5: O homem ejacula, e o esperma entra dentro do útero da mulher.

Professora: Ele entra diretamente?

Depois de olhar o texto novamente, responde:

Aluno 5: Não, ele faz um caminho.

Professora: Alguém saberia explicar?

Aluno 6: Ele passa pelas trompas até chegar no útero.

Professora: Você concorda com ela [aluno 5]?

Aluno 5: Concordo.

Professora: Vocês todos concordam com ela?

Aluno 2: Eu não

Aluno 9: Eu também não.

Outros se dividiram entre sim e não.

Professora: Por quê?

Aluno 19: Porque ele se encontra com o óvulo.

Professora: E aonde está o óvulo?

Aluno 19: Nas trompas.

Professora: Ele fica sempre ali?

Aluno 20: Não.

Aluno 3: Sim.

Professora: E o que acontece quando ocorre esse encontro?

Aluno 12: Eles vão para o útero.

Professora: Antes de irem para o útero,

o que acontece no encontro do espermatozóide com o óvulo? Leiam o texto novamente.

Aluno 19: Acontece a fecundação.
Aluno 9: Ela engravida, e o bebê vai para o útero.

Professora: Se ela engravidou, ela tem chance de ficar menstruada ainda?

Aluno 2: Agora não, só depois que ela ganhar neném.

Professora: Por quê?

Aluno 8: Porque agora ela está grávida, e mulher grávida não tem menstruação. Aluno 2: Porque aconteceu a ovulação.

Procurando saber se estavam seguros de suas respostas, a professora perguntou:

Professora: Quando vocês estavam grávidas, o que acontecia no corpo de vocês? Quais foram os primeiros sintomas que vocês sentiram quando engravidaram?

Aluno 6: Largura dos quadris.

Aluno 14: Enjôo. $\quad$ Aluno 2: Tontura, falta de menstruação.

Observamos que poucos alunos responderam que era a falta de menstruação, descreveram as reações e as características físicas externas, visíveis, aparentes, mas não chegaram ao processo que causavam sintomas como a tontura, o enjôo etc.

Embora não tenha sido falado propriamente o termo fecundação, a professora, objetivando perceber se tinham entendido a explicação, perguntou, então, o contrário desse processo:

Professora: Não havendo espermatozóide para fecundar o óvulo ou óvulos, o que acontece com o corpo da mulher? Aluno 14: Ela não engravida. Aluno 9: Ela fica menstruada.

Nesse momento, pelas respostas obtidas, pareceu-nos que, aos poucos, os alunos estavam manifestando alguma compreensão 
sobre alguns aspectos do conceito que estavam estudando. Para que o sujeito compreenda o conceito, bem como tome consciência dele, explica Sforni (2004, p. 79), os conceitos cotidianos devem atingir determinado nível de desenvolvimento, pois o domínio de um nível mais elevado na esfera dos conceitos científicos eleva o nível dos conceitos espontâneos. Em nossa pesquisa, houve momentos em que as informações recebidas contribuíram para que os conhecimentos espontâneos fossem, gradativamente, superados pelos científicos, contribuindo para a utilização consciente desse conceito.

Nesses debates foram discutidos alguns porquês que ainda estavam nebulosos para os alunos, porém não em sua totalidade. Verificamos que, a cada encontro, os alunos conseguiam estabelecer relações entre as conversas e as aulas que tinham. A cada aula, a participação da turma nos debates e nas atividades aumentava.

Apesar dos questionamentos que a professora fez sobre gravidez, menstruação, ovulação etc., durante várias aulas, suscitaram outras questões fundamentais relacionadas com a gravidez. No decorrer das aulas, de posse das informações e compreensão a que tinham chegado a respeito dos sistemas genitais, e buscando mais elementos que pudessem demonstrar o que os alunos compreenderam sobre essas discussões, a professora solicitou que os alunos respondessem a algumas questões:

Professora: O que vocês entenderam por menstruação?

Aluno 9: A menstruação é quando o útero se prepara para receber uma nova vida, mas quando isso não acontece, ele se desprende e forma o ciclo menstrual. Aluno 14: Menstruação é um ciclo que acontece de 28 em 28 dias, que acarreta vários problemas, como dor de cabeça, nervosismo, dores nos seios.

Professora: $O$ que você entende por cólica menstrual?

Aluno 13: A cólica menstrual ocorre porque o útero se prepara para receber o espermatozóide, quando isso não acontece, o útero se contrai e forma a cólica menstrual.

Aluno 15: A cólica menstrual ocorre devido à redução do útero que não recebe o espermatozóide e desce a menstruação, e nessa compressão do útero, causa a cólica.

Aluno 10: Porque o corpo está se preparando para receber um bebê e não recebe.

Aos poucos, começamos a perceber respostas mais elaboradas, que iam se distanciando das de senso comum, mesmo que ainda em alguns momentos alguns alunos oscilassem nas respostas.

\section{Considerações finais}

Os resultados obtidos com esse trabalho permitiram-nos compreender que a organização do ensino de conceitos científicos, se constitui num grande desafio para a escola contemporânea, quando entendemos o caráter sócio-histórico da formação dos sujeitos.

Com base na Teoria Histórico-Cultural, entendemos que mediação não se limita à relação entre sujeitos, pois diz respeito aos signos que, internalizados, passam a ser instrumentos psicológicos. Nesse sentido, não se trata apenas de interação entre professor e aluno ou entre os próprios alunos, mas, sobretudo, dos conhecimentos internalizados.

As análises das atividades de ensino observadas revelam que alguns alunos, mesmo tendo avançado na compreensão dos conteúdos sobre reprodução humana, não abandonaram conceitos espontâneos adquiridos na experiência prática. Segundo Moura (1999), as práticas culturais são elementos desencadeadores das funções psíquicas superiores, todavia, o desenvolvimento dessas funções, pode ser prejudicado 
se os indivíduos forem privados de uma efetiva inserção cultural, ou seja, se não tiverem acesso aos conhecimentos sistematizados via educação escolar.

A ação encaminhada pela docente demonstra o esforço em proporcionar aos estudantes elementos que pudessem contribuir para a ruptura com os saberes espontâneos, levando-os a compreender os processos que envolvem o funcionamento do corpo e a provocar reflexões capazes de levar a uma ação consciente diante dos fatos e fenômenos que o tema reprodução humana envolve. Os novos conceitos, como afirma Vygotsky, produzem uma nova visão sobre a realidade, como se os educandos estivessem olhando para o "espelho" de seus conhecimentos.

O confronto com os novos conhecimentos oportunizou aos alunos a reflexão sobre os conceitos que já haviam estudado. Isso foi revelado nas reflexões que fizeram, por exemplo, sobre as mudanças que ocorrem no corpo da mulher na época da ovulação, deixando ver que o acesso ao saber científico, possibilitou aos estudantes estabelecer relações entre a falta de menstruação e a gravidez. Diante da pergunta: manter relações sexuais estando menstruada engravida?, os alunos já conseguiam recorrer a alguns conceitos que estudaram e dar respostas mais fundamentadas.

Aos poucos, a compreensão explicitada pelos alunos possibilitou-lhes ir além das explicações pautadas em situações práticas, mostrando que a depender do modo como organizamos o ensino, este pode se tornar um fator decisivo na aprendizagem do aluno.

Das falas dos alunos depreendemos que, apesar das dificuldades, há indicadores de que houve modificação ou ampliação dos conhecimentos que tinham sobre reprodução humana e, com isso, a possibilidade de desenvolver novos níveis de atenção, percepção, raciocínio, imaginação.

É difícil sabermos se houve ou não uma efetiva apropriação conceitual pelos alu- nos da pesquisa, mas há fortes indícios de que a inserção desses alunos num movimento de reflexão foi fundamental para que possam ser mais conscientes nas ações que realizam.

\section{REFERÊNCIAS}

BRASIL. Constituição (1988). Constituição da República Federativa do Brasil. Brasília, DF: Senado Federal, 1998.

BRASIL. Congresso Nacional. Lei de Diretrizes e Bases da Educação Nacional, 1996.

KOSTIUK, S. Alguns aspectos da relação recíproca entre educação e desenvolvimento da personalidade. In: .; LURIA, A. R. et al. Psicologia e Pedagogia I: bases psicológicas da aprendizagem e do desenvolvimento. 2 ed. Lisboa: Editora Estampa, 1991.

LURIA, Aléxis Romanovich. Generalização e abstração. In: . Desenvolvimento cognitivo: seus fundamentos culturais e sociais. 2 ed. Tradução de: GURGUEIRA, Fernando Limongeli. São Paulo: Ícone, 1990.

MOURA, Tânia Maria de Melo. A prática pedagógica dos alfabetizadores de Jovens e adultos: contribuições de Freire, Ferreiro e Vygotsky. Maceió: Ed. da UFAL, 1999.

OLIVEIRA, Marta Kohl de. Analfabetos na sociedade letrada: diferenças culturais e modos de pensamento. In: Educação de Jovens e Adultos: novas perspectivas. Boletim Salto para o futuro. Tv Escola. set. 2001.

PALANGANA, Isilda Campaner; GALUCH, Maria Terezinha B.; SFORNI, Marta Sueli de Faria. Acerca da relação entre ensino, aprendizagem e desenvolvimento.

Revista Portuguesa de Educação, Lisboa, v. 15, n. 1, p. 111-128, 2002.

SFORNI, Marta Sueli de Faria. Aprendizagem conceitual e organização do ensino: contribuições da teoria da atividade. 1 ed. Araraquara: JM Editora, 2004.

VYGOTSKI, Lev Semyonovich. Obras escogidas II. Madrid: Visor, 1993.

. A construção do pensamento e da linguagem. Tradução Paulo Bezerra. São Paulo: Martins Fontes, 2000.

Pensamento e linguagem. 42 ed. São Paulo: Antídoto, 1979.

Pensamento e linguagem. São Paulo: Martins fontes, 1989. 